\title{
Medical Writing: Challenges in the Contemporary Era
}

\author{
Iqbal Hussain Udaipurwala
}

How to cite this Article:

Udaipurwala IH. Medical Writing: Challenges in the Contemporary Era. J Bahria Uni Med Dental Coll. 2022;12(1):1-2 DOI: https://doi.org/10.51985/JBUMDC2021107

This is an Open Access article distributed under the terms of the Creative Commons Attribution Non Commercial License (http:// creativecommons/org/licences/by-nc/4.0) which permits unrestricted non commercial use, distribution and reproduction in any medium, provided the original work is properly cited.

Publication of a research article in medical journal is reflection of scholarly activity and academic credentials. ${ }^{1}$ History of medical writing dates back to very ancient times but in the contemporary era, medical writing has been changed a lot and also changing continuously with each passing day. The time was not far in the past when the dictum "publish or perish" was popular but soon only "publish" was not enough. This noble statement is constantly changing its form to become "publish in a good journal or perish", then "publish in impact factor journal or perish", "publish in high impact factor or perish", "continuously publish in high impact factor journal or perish" and so on. Medical writing also became important in our region when academic promotions were made dependent on number of scientific publications. Publication in a well reputed scientific research journal with high impact factor is not an easy task and this is near to impossible who is writing for the first time. Writing skills are developed with practice and reading and it takes enormous patience and dedication to produce a research article. ${ }^{2}$

Being the part of editorial team in different scientific journals for about three decades, I had witnessed the major changes in practice and attitude in medical writing. The competition in clinical research and medical writing is increasing at tremendous rate. The amount of research papers and journal have been almost doubled during the last decade. ${ }^{3}$ Although, I know undoubtedly that writing a manuscript about 'writing' is very difficult and challenging and the task becomes more problematic when it is about medical writing. At one end, number of articles and research journals have increased, on the other hand the length and volume of each article has also been enlarged with word count reaching upto 5,000 words per article in some journal. As a result it is too difficult for a researcher to go through each article on a specific topic in detail. Due to digitalization and development of many scientific search engines and databases, searching is improved much but again it is too time consuming to go through every article. Researchers are overwhelmed by the load of scientific data available through different indexing agencies. The scientific volume over-load is a double edged sword, which

Iqbal Hussain Udaipurwala
Professor, Department of ENT
Bahria University Medical and Dental College
Email: udaipurwala@hotmail.com
Received: 17-Nov-2021
Accepted: 04-Dec-2021

is very beneficial for publicizing new research but may adversely affects the medical researcher in term of investing in time, resources, and funds etc. At this point, there is definitely a need to diminish excessive scientific volume load to increase the utility, efficiency and practicality and disseminating only the absolute essential information. The idea of decreasing volumes load bring the new concept of "lean and mean writing". This concept is still in its evolution phase and lot of efforts are required for designing proper guidelines, to make it practical and acceptable. For a new emerging researcher in health and medical field, time is very important and precious aspect in the race to complete everything on its scheduled timeline. Therefore, unnecessary and futile elaboration of the data that can be otherwise presented in a simple and straightforward way, should be restricted in medical writing.

The ease of access to the research data on the websites has surely increased and improved medical writing but on the other side of the coin, it has promoted the culture of plagiarism. ${ }^{4}$ This word was derived from a latin word "plagiarius" meaning kidnapping, to denote stealing of someone's else creative work as his own, which may be intentional or sometimes un-intentional. ${ }^{5}$ The plagiarism will result in unnecessary flooding of the research material with fabricated copy-pasted literature. ${ }^{6}$ It does not only involves stealing of words or phrases, but whole work and idea can be copied without giving due credit to the original worker. It is the basic requirement of contemporary era to cultivate zero-tolerance towards the plagiarism in medical writing. ${ }^{7}$ There can be different form of plagiarism depending upon the intent and extent of the copied material. ${ }^{8,9}$ The complete word to word work can be copied but sometimes words and sequence are changed by using synonyms and grammar, keeping the same meaning and idea as in the original work. There are many softwares available that are used by researchers, teachers, universities, journal editors to detect plagiarism in any work. Turnitin is among one of them and it is the most popular software in medical research and writing and was developed in the year $1997 .{ }^{10}$ The main drawback of these softwares is that it detect only similarity index depending upon the matching of words in any article and gives result in percentage. Even a $0 \%$ similarity index does not mean that the work is free from plagiarism, therefore human intervention is very important to rule out plagiarism after assessing the similarity index report. It is only the tip 
of the iceberg that we are visualizing in the sea of medical writing.

Another important concern related with the medical writing now a days is the issue of "ghost author" or "ghost writer". This term refers to a person who has prepared the scientific manuscript or contributed significantly in preparing manuscript but is not included in the list of authors. ${ }^{11}$ This problem was generated around two decades before when due to over-load in medical writing, professional medical writer turned-out and presently there are thousands of ghost authors around the world. They provide professional services related with all the aspect of medical writing and publishing in the scientific journals and charge their fees for this service. In addition, pharmaceutical companies promotes these ghost authors to publish research articles in good journals to enhance the growth of their products. ${ }^{12}$ At one end is the ethical assistance in preparing a medical manuscript for publication while on the other hand there is an unethical and funded ghost author who prepares an article and publish it with the names of other researcher in the field. The line of demarcation between these two is very vague and unclear. Professional medical writer may help a clinician to publish his research in a proper way which otherwise is difficult to get published by a clinician who is busy with his/her practice, so this professional assistance will prevent loss of important data. Secondly quality of the published article will be much better if it is written by a professional medical writer. The International Committee of Medical Journal Editors (ICMJE) and World Association of Medical Editors (WAME) have established policies on specific criteria for scientific authorship. The contribution of each author during the preparation of a research article must be submitted and published along with the manuscript. If the services of a professional medical writer has been sought, it should be mentioned in the acknowledgment section properly. A lot of efforts are required by the international regulating agencies and medical journal editors to deal with this issue of ghostwriting.

Workshops on medical writing and medical research are being organized by different universities, medical societies and medical education departments and now, even at undergraduate level medical writing is being taught. New medical researchers and intended authors are advised to formally attend these workshops before writing an article. There is also need of standardized hand-on workshops at all levels including under-graduates, post-graduates and consultants, as medical writing is a science and art that has to be learned and practice.

Authors Contribution:
Iqbal Hussain Udaipurwala: Substantial contributions to the |
conception criticaly evaluation of intellectual content, final
approval of the version to be published

\section{REFERENCES:}

1. Tullu MS, Karande S. Writing a model research paper: A roadmap. J Postgrad Med. 2017; 63(3): 143-146. doi: 10.4103/ jpgm.JPGM_325_17

2. Aziz S. Basic guide to scientific writing. J Pak Med Assoc, 2012; 62(10):1105-6. PMID: 23866461

3. Bhardwaj P, Sinha S, Yadav RK. Medical and scientific writing: Time to go lean and mean. Perspect Clin Res, 2017; 8:113-7. DOI: 10.4103/picr.PICR_11_17

4. Oermann MH, Nicoll LH, Chinn PL, Ashton KS, Conklin JL, Edie AH, et al. Quality of articles published in predatory nursing journals. Nurs Outlook 2018; 66: 4-10. DOI: 10.1016/ j.outlook.2017.05.005

5. Masic I. Plagiarism in scientific publishing. Acta Inform Med 2012; 20: 208-13. DOI: 10.5455/aim.2012.20.208-213

6. Masic I. Plagiarism in scientific research and publications and how to prevent it. Mater Sociomed 2014; 26: 141-6. DOI: 10.5455/msm.2014.26.141-146

7. Sharmaa H, Vermab S. Insight into modern-day plagiarism: The science of pseudo research. Tzu Chi Medical Journal, 2020; 32(3): 240-244 DOI: 10.4103/tcmj.tcmj_210_19

8. Das N. Intentional or unintentional, it is never alright to plagiarize: A note on how Indian Universities are advised to handle plagiarism. Perspect Clin Res 2018; 9: 56-7. DOI: 10.4103/picr.PICR_140_17

9. Kumar PM, Priya NS, Musalaiah S, Nagasree M. Knowing and avoiding plagiarism during scientific writing. Ann Med Health Sci Res, 2014; 4: S193-8. DOI: 10.4103/2141-9248. 141957

10. Meo SA, Talha M. Turnitin: Is it a text matching or plagiarism detection tool? Saudi J Anaesth 2019; 13: S48-51. DOI: 10 4103/sja.SJA_772_18

11. Yadav S, Rawal G. Ghostwriters in the scientific world. Pan African Medical Journal. 2018; 30: 217. DOI:10.11604/pamj. 2018.30.217.16312

12. Dotson B, Slaughter RL. Prevalence of articles with honorary and ghost authors in three pharmacy journals. Am J Health Syst Pharm. 2011; 68(18): 1730-4. DOI: 10.2146/ajhp100583

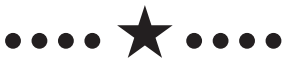

